\title{
CONSTITUIÇÃO DE UM GRUPO COLABORATIVO EM EDUCAÇÃO MATEMÁTICA COM PROFESSORAS EM INÍCIO DE CARREIRA
}

\author{
Establishment of a collaborative groups in Mathematical education with teachers at \\ beginning of career
}

\section{Constitución de un grupo colaborativo en educación Matemática con profesoras en inicio de carrera}

\author{
Klinger Teodoro Ciríaco ${ }^{1}$ \\ Maria Raquel Miotto Morelatti ${ }^{2}$ \\ João Pedro da Ponte ${ }^{3}$
}

\begin{abstract}
Resumo
Analisamos contribuições da constituição de um grupo de trabalho colaborativo, com professoras em início de carreira, a partir das interações entre as integrantes no sentido da superação das suas dificuldades em aulas de Matemática. Para este fim, adotamos uma metodologia de trabalho estruturada na pesquisa-ação estratégica, com o objetivo de auxiliar as docentes em problemas experienciados durante o processo do aprender a ensinar nos primeiros anos de profissão. Os dados coligidos e referenciados neste artigo visam apresentar percepções sobre o movimento percorrido pelo grupo e as implicações destas ações na prática pedagógica. Concluímos que o espaço coletivo possibilitado pelo compartilhamento das experiências profissionais pode ser a base para a implementação de iniciativas de apoio à inserção profissional no período de indução.
\end{abstract}

PALAVRAS-CHAVE: Grupo colaborativo. Professoras Iniciantes. Ensino de Matemática.

\begin{abstract}
We have analyzed constributions arising from the establishment of a work group of teachers in their early careers, taking the interactions among the members towards overcoming their difficulties in Mathematics classes. For that goal, we adopted a working methodlogy structured on the researchaction strategy, with the purpose of helping those teachers to deal with problems they experiencied during the process of learning how to teach in the first years of the profession. The data we were able to collect and utilized in this paper aim to present the perceptions about the path taken by the group and the implications of such actions onto the pedagogical practice. Our conclusion is that the collective ambience resulting for the sharing of professional experiences may be the basis to implement initiatives intended to support the transition to work in the period of induction.
\end{abstract}

KEYWORDS: Collaborative group. Fresh teachers. Teaching Mathematics.

\footnotetext{
${ }^{1}$ Pós-Doutor em Psicologia da Educação Matemática pelo Programa de Pós-Graduação em Educação para a Ciência da UNESP, Câmpus Bauru. Professor Adjunto e Coordenador do Curso de Pedagogia da Fundação Universidade Federal de Mato Grosso do Sul (UFMS, Câmpus de Naviraí). Docente Permanente do Programa de Pós-Graduação em Educação Matemática do Instituto de Matemática da UFMS. E-mail: klingerufms@hotmail.com

${ }^{2}$ Doutora em Educação (Currículo) pela PUC/SP (2001) e mestre em Matemática pela UFSCar (1992). É professora assistente junto ao Departamento de Matemática e Computação (DMC) e atualmente coordenadora do Programa de Pós-Graduação em Educação (PPGE) da Faculdade de Ciências e Tecnologia (FCT), UNESP, Campus de Presidente Prudente (2017-2021). E-mail: mariaraquelmm@gmail.com

${ }^{3}$ Professor catedrático de Didática da Matemática, licenciado em Matemática pela Universidade de Lisboa. Doutor em Educação Matemática pela Universidade da Georgia (EUA). Email: jponte@fc.ul.pt
} 


\section{Resumen}

Se analizan las contribuciones de la constitución de un grupo de trabajo colaborativo, con maestras en inicio de carrera, a partir de las interacciones entre las integrantes en el sentido de la superación de sus dificultades en las clases de Matemáticas. Para este fin, adoptamos una metodología de trabajo estructurada en la investigación-acción estratégica, con el objetivo de auxiliar a las docentes en problemas experimentados durante el proceso del aprendizaje a enseñar en los primeros años de profesión. Los datos recopilados y referenciados en este artículo apuntan a presentar percepciones sobre el movimiento recorrido por el grupo y las implicaciones de estas acciones en la práctica pedagógica. Concluimos que el espacio colectivo posibilitado por el compartir las experiencias profesionales puede ser la base para la implementación de iniciativas de apoyo a la inserción profesional en el período de inducción.

PALABRAS CLAVE: Grupo colaborativo. Profesores principiantes. Enseñanza de Matemáticas.

\section{INTRODUÇÃO}

No cotidiano da nossa profissão temos acompanhado o percurso de futuros professores ao longo do processo de formação inicial, identificando alguns desafios ainda existentes nesse processo que acabam por gerar sérias dificuldades na atuação profissional.

Nesta perspectiva, a tese que originou este artigo inscreve-se num esforço de compreensão do processo de iniciação à docência a partir de uma experiência colaborativa com um grupo de professoras, que ensinam Matemática, nos seus primeiros anos de carreira, sendo estas com os seguintes nomes fictícios: Alice, Bianca, Paula, Stella e Sofia. Trata-se de um estudo das relações de aprendizagem da docência, a partir do movimento colaborativo, decorrente da interação e do compartilhamento das experiências.

A pesquisa procurou apontar possibilidades da colaboração como forma de superação das dificuldades didático-pedagógicas em relação ao ensino dos conteúdos matemáticos. A questão central a que procuramos responder é saber que contribuições as interações entre professoras com perfis de formação distintos (Matemática e Pedagogia) podem oferecer para o processo de aprendizagem da docência em um contexto de colaboração.

\section{Grupos colaborativos na formação de professores}

No Brasil, os grupos com características colaborativas surgiram no cenário dos estudos e da prática em universidades nos anos 90, momento em que se tornou frequente a parceria entre professores universitários e professores da Educação Básica. $\mathrm{O}$ foco desses momentos era a reflexão sobre as práticas do aprender a ensinar no contexto da escola, sob a perspectiva de contribuir com um melhor desempenho na prática docente.

Crecci e Fiorentini (2012, p. 1) consideram que esse fato "foi decorrente da mudança de concepção das práticas de formação de professores, tendo em vista a relação entre formação acadêmica e prática profissional”.

Fiorentini e Lorenzato (2006) afirmam que, no caso da Educação Matemática, a maior parte desses grupos cresceu a partir da vinculação de docentes que trabalham com o ensino dos conteúdos matemáticos, em espaços acadêmicos dos grupos de pesquisa.

A relevância dos grupos para a formação de professores é inegável na medida em que proporcionam o rompimento com o isolamento, uma vez que, no espaço compartilhado, 
os professores têm maiores chances de colaborar e desenvolver posturas investigativas sobre o processo de ensino e aprendizagem dos seus alunos e a sua aprendizagem da docência. Para Fiorentini (2004), um grupo colaborativo procura, no desenvolvimento das suas ações, compartilhar objetivos, problemas e experiências no sentido de atingir metas comuns entre os intervenientes. "O trabalho colaborativo possibilita, além disso, o resgate de valores como o compartilhamento e a solidariedade - que se foram perdendo ao longo do caminho trilhado por nossa sociedade, extremamente competitiva e individualista" (DAMIANI, 2008, p. 225).

Muitos professores, pela excessiva carga horária de trabalho nas escolas, acabam por não ter acesso e/ou oportunidade a momentos de reflexão sobre a prática pedagógica e tal situação gera ações dissociadas da tomada de consciência. Nesse contexto, os grupos colaborativos podem ser considerados uma alternativa que contribui para o desenvolvimento profissional dos professores, uma vez que as aprendizagens oportunizadas nesse espaço tiram o professor do isolamento, apresentando-lhe a colaboração como elemento constitutivo das suas ações.

Fullan e Hargreaves (2000) consideram que o isolamento docente surge em decorrência da arquitetura das escolas, estrutura dos horários de funcionamento, a carga excessiva de trabalho, bem como a própria história da profissão de professor. Outros autores, como Engeström (1994) e Pimenta (2005), corroboram nesse entendimento ao relacionarem tais questões com as escolas brasileiras.

Damiani (2008), em estudos sobre os benefícios do trabalho colaborativo para a educação, aponta que os professores brasileiros estão a maior parte do tempo 'livres', dispersos na escola. Para a autora,

Há momentos de organização, como nos encontros nas salas de professores, nos conselhos de classe, nos grupos que trabalham com as mesmas disciplinas ou nos horários de trabalho pedagógico coletivo. Esses momentos, entretanto, acabam sendo utilizados muito mais para a realização de atividades burocráticas [...] (DAMIANI, 2008, p. 219).

Para Martins (2002, p. 233), os professores passam grande parte do tempo considerado "livre" ou de planejamento dentro das escolas a trabalhar para cumprir questões burocráticas e na resolução de questões pontuais, ao invés de constituir "um espaço para reflexão, planejamento e transformação de sua prática educacional em atividades humanizadoras para si mesmo e para seus alunos".

Pode-se fazer a ilação que os professores sozinhos não obterão muito êxito nessa tarefa, pela qual é necessário procurar parcerias em outras instâncias como, por exemplo, nas universidades em projetos coletivos/colaborativos de pesquisa, conforme evidencia Giovanni (2009). Tais ações precisam gerar oportunidades de "vivência dos processos de produção do conhecimento pelos professores e de diálogo entre os diferentes profissionais do ensino (pesquisadores universitários, professores, diretores, coordenadores pedagógicos)" (GIOVANNI, 2009, p. 17-18).

A cooperação entre ensino, pesquisa e atitudes de investigação em relação à própria prática, tornam-se pontos significativos para formação dos professores, tanto inicial quanto contínua. Logo, "os professores que participam dos grupos colaborativos desenvolvem uma profissionalidade interativa e reflexiva, podendo ser, em alguns casos, também 
investigativa" (CRECCI; FIORENTINI, 2012, p. 2), o que pode auxiliar na superação das dificuldades didático-pedagógicas.

Os integrantes do grupo, independente do espaço de atuação pedagógica, podem ser considerados como protagonistas do seu desenvolvimento profissional e dos colegas, na medida em que as suas experiências de vida e de formação contribuem para a prática dos demais participantes, que no caso desta pesquisa, faz toda a diferença, uma vez que, as professoras são iniciantes e têm uma prática comum: o ensino de Matemática. "Esse 'outro', por ser diferente, permite que eu reflita mais sobre meu fazer ao compartilhar com ele este fazer" (CRISTOVÃO, 2009, p. 25). Assim, o ato de explicitar as experiências pessoais tornase uma tarefa de reflexão das ações pedagógicas.

\section{Delineamento metodológico e constituição do grupo}

Este estudo tem por base reflexões sobre a prática pedagógica de quatro pedagogas e uma professora de Matemática, realizadas em encontros ocorridos quinzenalmente no período de agosto de 2013 a julho de 2015. Todas as professoras, durante a realização do trabalho de campo, estavam em atuação em escolas públicas e privadas da rede municipal e/ou estadual de Naviraí, no interior do estado de Mato Grosso do Sul. O objetivo das ações realizadas teve como base, compreender as possíveis contribuições do compartilhamento das experiências entre as participantes, durante os primeiros anos na profissão para a aprendizagem da docência.

O perfil do grupo é bem diversificado, com professoras que lecionam tanto na rede pública de ensino quanto na particular, conforme disposto no quadro 1 :

QUADRO 01 - Caracterização das professoras iniciantes participantes do grupo

\begin{tabular}{|c|c|c|c|c|}
\hline PROFESSORA & IDADE/FORMAÇÃO & $\begin{array}{c}\text { TURMA } \\
\text { QUE ATUA }\end{array}$ & $\begin{array}{l}\text { TEMPO DE } \\
\text { ATUAÇÃO }\end{array}$ & $\begin{array}{c}\text { SISTEMA } \\
\text { ESCOLAR }\end{array}$ \\
\hline ALICE & $\begin{array}{c}21 \text { anos - Licenciatura } \\
\text { em Pedagogia }\end{array}$ & $\begin{array}{l}\text { Educação } \\
\text { Infantil - } \\
\text { Maternal }\end{array}$ & 02 anos & Particular \\
\hline BIANCA & $\begin{array}{c}29 \text { anos - Licenciatura } \\
\text { em Matemática }\end{array}$ & $\begin{array}{c}\text { Ensino } \\
\text { Fundamental } \\
-6^{\circ} \text { e } 7^{\circ} \text { ano }\end{array}$ & 02 anos & Público estadual \\
\hline STELLA & $\begin{array}{l}27 \text { anos - Licenciatura } \\
\text { em Pedagogia com Pós- } \\
\text { graduação em Educação } \\
\text { Infantil e Séries Iniciais }\end{array}$ & $\begin{array}{c}\text { Ensino } \\
\text { Fundamental } \\
-3^{\circ} \text { ano }\end{array}$ & 01 ano & $\begin{array}{l}\text { Público } \\
\text { municipal }\end{array}$ \\
\hline SOFIA & $\begin{array}{c}23 \text { anos - Licenciatura } \\
\text { em Pedagogia }\end{array}$ & $\begin{array}{c}\text { Ensino } \\
\text { Fundamental } \\
-5^{\circ} \text { ano }\end{array}$ & 03 anos & Particular \\
\hline
\end{tabular}




\begin{tabular}{|c|c|c|c|c|}
\hline & 32 anos - Normal & Ensino & & \\
PAULA & Superior e Licenciatura & Fundamental \\
em Pedagogia & $-3^{\mathbf{o}}$ ano & 03 anos & $\begin{array}{c}\text { Público estadual } \\
\text { e municipal }\end{array}$ \\
\hline
\end{tabular}

Fonte: CIRÍACO (2016, p. 155).

Com relação à formação inicial das professoras, todas são egressas de cursos de Pedagogia e Matemática de instituições locais e/ou próximas ao município de Naviraí/MS.

Alice e Sofia são ex-alunas do curso de Pedagogia da Universidade Federal de Mato Grosso do Sul - UFMS, portanto, foram alunas do primeiro autor. Stella e Paula são egressas do curso de Pedagogia das Faculdades Integradas de Naviraí/MS - FINAV - e Bianca graduou-se no curso de licenciatura em Matemática da Universidade Estadual de Mato Grosso do Sul - UEMS.

Os nomes das professoras são fictícios de modo que garanta a sua integridade, bem como o anonimato com vista a não as prejudicar profissionalmente pela participação no estudo, tendo sido escolhidos pelas próprias.

Em relação às reuniões, a proposta fundamentou-se em encontros quinzenais ocorridos nas dependências de uma escola estadual em que pesquisador e professoras iniciantes discutiram/refletiram problemas vivenciados nas aulas de Matemática com vista à sua superação, a partir da prática de colaboração.

A periodicidade dos encontros durante o ano de 2013 foi quinzenal, com duração média de 1h40min e, em 2014 e 2015, passou a ser mensal, aumentando a sua duração para 2 horas de trabalho/discussão a partir do planejamento das professoras. Ou seja, os encontros passaram a ser orientados com base nos conteúdos matemáticos que as participantes abordavam nas turmas em que atuavam.

De acordo com a necessidade formativa das professoras, cada uma apresentava o modo como conduzia as suas aulas e as restantes opinavam sobre como se poderia melhorar a prática em sala de aula ou ainda esclareciam como ministrar o tema discutido, prática essa que ampliou a capacidade do grupo no que diz respeito as formas de abordagem dos conteúdos.

Ressaltamos ainda que a potencialidade desta intervenção de colaboração encontra respaldo no fato de que diferentes olhares sobre o ensino, devido aos diversos níveis e lugares nos quais cada professor participante do grupo se insere ${ }^{4}$, permite uma riqueza de experiências que, ao serem compartilhadas com o "outro" possibilita a reflexão individual sobre a ação pedagógica. "O próprio ato de compartilhar torna-se uma tarefa reflexiva, pois preciso pensar como dizer sobre o que eu faço e depois preciso interpretar o que o outro está entendendo sobre o que eu digo" (CRISTOVÃO, 2009, p. 25).

\section{O processo vivenciado pelo grupo}

\footnotetext{
${ }^{4}$ Temos consciência de que, os conteúdos curriculares ensinados, pela via da prática do professor, são diferentes por se tratarem de dois níveis da Educação Básica $\left(1^{\circ}\right.$ ao $5^{\circ}$ ano no caso dos pedagogos e $6^{\circ}$ ao $9^{\circ}$ ano com os professores de Matemática). Porém, acrescentamos que é aí que se encontra a relevância desta interação. Pela tradição escolar, os alunos que ingressam na segunda etapa do Ensino Fundamental $\left(6^{\circ}\right.$ ao $\left.9^{\circ}\right)$ aprenderam Matemática com o professor formado em Pedagogia e agora serão ensinados por professores da área específica.
} 
A dinâmica da pesquisa-ação (FRANCO, 2005) englobou neste estudo os seguintes aspectos:

$1^{\text {0) }}$ Aclarar e diagnosticar uma situação prática ou um problema prático que se quer melhorar ou resolver - esse foi o ponto de partida para a constituição do grupo de trabalho colaborativo, composto por professoras iniciantes licenciadas em Pedagogia e Matemática.

A partir destes relatos, pesquisador e professoras iniciantes começaram a refletir sobre quais as medidas e as estratégias de ação que poderiam ser sugeridas e/ou formuladas para "experimentação" na procura de melhorar as situações expostas pelo grupo. E assim, se iniciou o segundo passo do trabalho colaborativo.

$\mathbf{2}^{\circ}$ ) Formular estratégias de ação - com base nas considerações expostas pelas colaboradoras da pesquisa, começamos então, a formular algumas estratégias/medidas de apoio e superação das dificuldades.

A maioria das professoras chegou a um consenso de que a relação com a matéria de ensino (Matemática) era a questão a ser tratada em primeira instância. Precisavam superar alguns mitos em relação a essa área do conhecimento, bem como pensar em estratégias metodológicas para o ensino dos conteúdos matemáticos de modo que se atingisse o interesse dos alunos.

O fato de termos uma professora de Matemática no grupo possibilitou às licenciadas em Pedagogia uma visão mais abrangente de conteúdos ${ }^{5}$. As intervenções dessa professora constituíram um apoio na compreensão específica de alguns conteúdos que tinham que ensinar. De forma semelhante, a interação com as pedagogas oportunizou à professora de Matemática uma compreensão mais pedagógica das formas de abordagem e estratégias de ensino para os seus alunos da segunda etapa do Ensino Fundamental.

Após o debate coletivo, traçamos um planejamento das ações que iríamos desenvolver na sala de aula. A implementação das ações oportunizadas pela troca de experiência entre as professoras, ocorreu de modo natural e espontâneo.

$3^{\text {o }}$ ) Desenvolver essas estratégias e avaliar sua eficácia - Em reuniões posteriores as trocas de informações e experiências do modo como cada professora conduzia a sua aula, as reuniões do encontro do grupo eram abertas com relatos espontâneos sobre como estávamos a desenvolver as aulas de Matemática.

Assim, tentávamos validar as ações pedagógicas a partir da prática das integrantes, o que ampliava a compreensão das situações vivenciadas e da aprendizagem dos aspectos e especificidades da docência.

$4^{\circ}$ ) Ampliar a compreensão da nova situação - Os círculos de reflexão sobre a ação das integrantes permitiram ampliar o repertório de ideias e compreender situações didáticas para as quais ainda não tínhamos atentado. Isso revelou algumas características que não prevíamos durante o planejamento das ações, tais como: as atitudes dos alunos em relação aos conteúdos matemáticos; os sentimentos das próprias professoras no momento da sua atuação; as reflexões sobre como ensinar aquilo que nem sempre se aprendeu na formação inicial; o reconhecimento de que era preciso conhecer as propriedades da matéria

\footnotetext{
${ }^{5}$ A análise da contribuição desta interação entre professores da licenciatura em Matemática e em Pedagogia também será abordada na próxima seção.
} 
de ensino, e que não basta apenas saber princípios metodológicos da abordagem dos conteúdos, entre outras.

Essas situações conduziram-nos ao ponto de partida inicial da constituição do grupo: avaliar e diagnosticar problemas práticos. Isso possibilitou-nos, em conjunto, identificar que a carreira de um professor está em construção permanente.

$5^{\circ}$ ) Proceder aos mesmos passos para a nova situação prática - assim, chegamos aqui, ao quinto passo da pesquisa-ação. Professoras iniciantes e pesquisador viram-se face às situações aparentemente "velhas", já conhecidas pelo grupo, mas que, dado o contexto em que a mesma se apresentava, não era possível superá-la com a solução encontrada anteriormente.

Esse fato levou-nos a uma nova fase da pesquisa e da prática pedagógica: a reflexão sobre as ações e atitudes, com vista a novos caminhos do fazer docente em sala de aula. doutorado.

A figura 1 ilustra a dinâmica de colaboração que resultou na constituição da tese de

FIGURA 01 - Dinâmica da vivência colaborativa do grupo deste estudo.

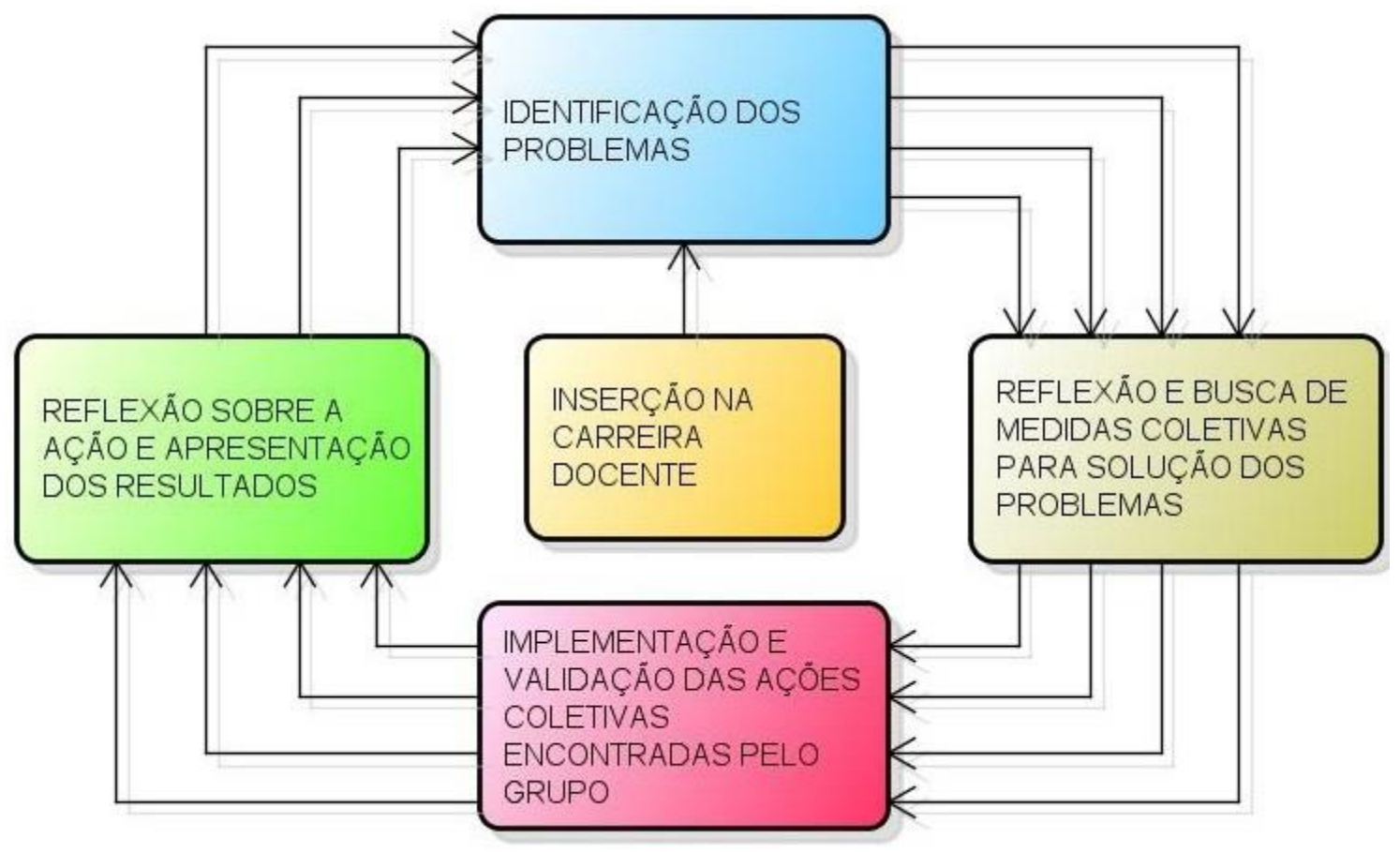

Fonte: (CIRÍACO, 2016, p. 208).

O direcionamento da mediação no grupo seguiu uma relação dialógica e espiral, pois, durante toda vivência, passamos pelos pontos de identificação dos problemas da prática docente no ensino dos conteúdos matemáticos; refletimos formas de superação a partir da negociação entre os diferentes pontos de vista; implementamos e validamos algumas das ações, retomando os conteúdos nas turmas em que as professoras atuavam e, posteriormente, retornávamos a reflexão sobre a ação como um elemento estruturante e permanente para viabilizar a prática colaborativa. 
Ao final de cada ciclo reflexivo, voltava-se ao processo inicial, uma vez que a carreira docente é encarada neste estudo como um processo contínuo e, portanto, a lógica desse movimento espiral permite compreender a docência em sua práxis como um processo dialético que se (re)inicia a cada novo ano letivo escolar.

A constituição do grupo de trabalho com o enfoque nos problemas vivenciados pelas professoras no percurso do aprender a ensinar Matemática, durante os primeiros anos da docência afirmou-se, na experiência aqui relatada, como um momento de autonomia profissional, uma vez que nesse espaço, cada integrante toma decisões perante os desafios enfrentados e confrontados na prática escolar.

\section{Discursos que se entrecruzam: $o$ antes e o depois da inserção no grupo colaborativo}

No caso pesquisado, todas as professoras iniciantes apresentaram um ideário da profissão docente ligado à experiência, quando questionadas sobre a escolha das suas carreiras. Apontaram justificações importantes em relação às contribuições do grupo que constituímos para o seu processo de iniciação à docência. Na maioria das respostas aparece a troca de ideias e de experiência, a possibilidade de sanar dúvidas, o apoio nas dificuldades e a questão afetiva entre as participantes, como sendo elementos recorrentes no espaço do grupo. Estas foram as expectativas iniciais de Alice e Sofia:

Eu já imaginava que seria uma troca de ideias (...) e não foi nada diferente do que eu achei. Achei que a gente ia trocar ideias entre nós, as professoras iam levar exemplos, sanar as nossas dúvidas, então assim, eu não tinha uma visão muito diferente do que seria esse grupo (ALICE, Naviraí-MS, 2013).

Pensava que ia ser um grupo para ajudar, para ter outra visão, para melhorar a maneira de você trabalhar, buscar outras maneiras (SOFIA, Naviraí-MS, 2013).

Bianca, Paula e Stella, afirmaram ter algumas restrições em relação à sua vinculação nesse espaço, uma vez que acreditavam que nesses encontros ouviriam mais do mesmo. Seria restrito às questões teóricas, relativo ao ensino de Matemática pelo pesquisador. A visão de formação em contexto, a partir das suas experiências, fez com que pensassem que no grupo seriam apenas "plateia" e que ali ocupariam mais um espaço na cadeira durante o tempo em que se dedicassem a essa atividade:

Eu achei que a reunião seria ensinamento de matemática [risos] (BIANCA, Naviraí-MS, 2013).

Eu achei que ia ser teoria, só teoria, teoria, teoria, teoria. Tipo, pegar textos e estudar textos. Eu achei que ia ser assim "mais um curso de ficar estudante texto, texto", mas não, não foi, foi uma troca de experiências. [...] eu achei que fosse estudo de textos relacionados à matemática, mas achei que fosse estudo de textos de você pegar a "apostilinha", aquelas coisinhas ali, eu achei (PAULA, NaviraíMS, 2013).

Eu imaginava que ia ser uma coisa bem maçante, bem chata. Essa era a minha visão. Eu já imaginava que iria me trazer algum conhecimento, mas imaginava aquela coisa chata, muita abobrinha. E realmente a minha visão que eu tenho hoje é totalmente diferente, é muito bom o grupo! (STELLA, Naviraí-MS, 2013). 
No decorrer dos encontros, as professoras puderem perceber que a dinâmica de trabalho com o enfoque colaborativo as retiraram da "plateia" e as colocaram no "palco", convidando-as a serem protagonistas da sua construção na peça teatral que seria, no futuro, o início da sua carreira.

Por outras palavras, o movimento do grupo, a partir da inserção e interação das suas integrantes, fez com que cada professora se tornasse mais autônoma na sua atuação e, consequentemente, na sua capacidade reflexiva.

Enfim, o grupo tornou-se um espaço com características colaborativas, na medida em que lhes possibilitou uma relação de confiança com os outros os membros, ao expressarem de forma espontânea os seus sentimentos e as formas de pensamento em relação às críticas e possibilidades de transformação da prática pedagógica.

As professoras declararam que, após a inserção no grupo, tiveram mais segurança e apontaram as contribuições desse ambiente para as suas práticas, como sendo a possibilidade de compartilhar experiências em relação à Matemática e o processo de negociação dos significados atribuídos ao ensino e aprendizagem, a partir da vivência individual no contexto/cenário em que atuavam:

\begin{abstract}
O grupo me ajudou muito e, eu pretendo continuar nele [risos]. Me ajudou muito, por que como eu sou professora da Educação Infantil tinha professoras do Ensino Fundamental e eu pretendo pegar o Ensino Fundamental esse ano não ficar apenas na Educação Infantil, então assim, coisas que eu nunca tinha entendido as professoras puderam me esclarecer de um jeito mais fácil de estar passando aos alunos, complicar menos (ALICE, Naviraí-MS, 2015).

Depois eu vi que era uma troca de experiência e também para gente conseguir ir entendendo como eu trabalho com um assunto e como outro trabalha e, ver também que os conteúdos trabalhados ao longo dos anos, cada ano um pouquinho e ai eu vi que era um complemento. É o que a gente vive falando, mas a gente tem impressão de que o colega fala de uma forma totalmente diferente, ai eu fui vendo que é um complemento mesmo. (BIANCA, Naviraí-MS, 2013).

Nosso bate papo é uma troca de experiência, eu conto a minha vivência, você conta a sua vivência a gente troca experiência um com o outro (PAULA, Naviraí-MS, 2015).

Eu pego bastante as coisas que vocês falam no grupo. E eu vejo assim que é uma superação, falar assim: "nossa a dificuldade não é só minha tem um monte de gente com dificuldade" e é a visão acho que de todos. Ai você fala assim: "não é só eu que tenho dificuldade, todo mundo tem dificuldade" (SOFIA, Naviraí-MS, 2015). Estar no grupo hoje, me trouxe muita coisa, me acrescentou muita coisa. É muito produtivo. É realmente uma troca de ideias. (STELLA, Naviraí-MS, 2015).
\end{abstract}

O gerenciamento das ações desenvolvidas foi um aspecto importante para que a interação entre os diferentes níveis de atuação no ensino de Matemática ocorresse de modo produtivo, pois as reuniões foram planejadas inicialmente com base na necessidade formativa das integrantes e, posteriormente, em concordância com o seu planejamento em relação às temáticas que estavam a abordar. É claro que esse processo não foi possível em todas as reuniões, contudo, procurávamos sempre atender a emergência da prática logo que constatavam dificuldades, tanto conceituais quanto metodológicas. Isso possibilitou aproximarmo-nos dos aspectos que compõem o rol de características dos grupos colaborativos. 
Como anunciam as falas de Alice, Bianca, Paula, Sofia e Stella o grupo possibilitou o acesso a uma gama de possibilidades do trabalho coletivo em relação aos assuntos que foram identificados como dificuldades no começo da carreira docente. Na experiência, trabalhar mais próximo com professoras iniciantes de perfis e trajetória de vida e formação distintas, possibilitou-nos compreender que a atividade docente vai muito para além do desenvolvimento de ações estratégicas com o foco nos objetivos, pois o que era "meu" tornou-se "nosso".

Alice, Bianca e Sofia caracterizam a mudança de concepção que tiveram, quando esclarecem respectivamente que: aprenderam coisas nunca antes compreendidas com a troca de ideias, o ato de "ouvir" o outro tornou-se mais significativo para a prática individual e que as dificuldades tornaram-se um problema para grupo e não mais um obstáculo pessoal. Encontramos aqui mais um ponto do trabalho colaborativo, a confiança e o respeito mútuo.

Na nossa experiência de trabalho, com enfoque na "colegialidade" e "colaboração", construímos com as professoras uma cultura de produção e sistematização de conhecimentos práticos da docência, a partir da problematização das suas vivências. Com isso, acreditamos ter possibilitado uma reciprocidade de aprendizagem, ao passo que defendemos, nesta tese, que a aprendizagem da docência em Matemática é um processo colaborativo e, portanto, tem fortes influências e contribuições do olhar do "outro" para e sobre a minha prática, momento este em que nos constituímos em sujeitos, tanto da aprendizagem quanto do ensino.

A participação em grupos pode contribuir para o processo de desenvolvimento profissional dos professores e, no caso deste estudo, especificamente para o processo também de iniciação à docência em Matemática. As professoras colaboradoras não se encontram mais "sozinhas", fazem parte de uma comunidade de pesquisa-ação que teve como propósito apoiá-las no percurso de estratégias tanto metodológicas quanto específicas de ensino, em relação às suas dificuldades didático-pedagógicas, decorrentes da formação inicial que não oportunizou relacionar teoria e prática.

A prática colaborativa pode permitir também que o professor, realize uma mudança de paradigma de ensino, quando passa a desenvolver, a partir da partilha com o outro, posturas diferentes e exploratórias no processo de ensino e aprendizagem. Isso foi perceptível para a professora Bianca, quando relata a importância de conviver com um grupo de pedagogas:

Para mim, acho que fiquei mais humana com os meus alunos [Risos]. Eu tento entender também que eles talvez não tenham chegado assim, não estão do jeito que quero que eles estejam porque também nós não estamos do jeito que queríamos que fosse [Risos], mas a gente têm sempre essa mania de jogar a culpa nos outros e, acho que com o grupo a gente está procurando se ajudar e não se acusar "ah você não fez isso"; "ai outro professor deixou de fazer aquilo", a gente está tentando se ajudar [...] Porque antes, achava que eu tinha que chegar com determinado conteúdo explicar aquilo ali e eles [alunos] tinham que, dali para frente, eles teriam que saber e pronto. "Ah professora eu não sei. Ah não sabe?". Era assim, agora não! Já tento explicar de novo, penso também sobre a vida do aluno, já penso estas outras coisas que antes, eu não pensava muito. Achava que tinha que ser e pronto, e aqui no grupo, convivendo com as professoras que têm formação em Pedagogia, vejo o grande esforço delas para ensinar Matemática às crianças e, ao mesmo tempo, as dificuldades e limitações decorrentes da formação (BIANCA, Naviraí-MS, 2015).

A vinculação desta professora a um grupo de professoras da área mais pedagógica, no sentido dos princípios da formação como é o caso do curso de Pedagogia, parece ter 
desencadeado um processo de contribuição para a aquisição do conhecimento pedagógico da matéria de ensino, como também uma mudança de paradigma nas suas aulas, quando relata que atualmente tenta compreender mais o lado dos seus alunos e apoiá-los na superação das suas dificuldades, ao procurar novas formas de abordagem dos conteúdos de maneira mais detalhada, o que não acontecia antes dessa interação com Alice, Paula, Sofia e Stella, ou seja, Bianca parece ter incorporado, na sua prática, uma visão mais exploratória e investigativa de ensino.

Abandonar a zona de segurança, em que as aulas se baseavam em procedimentos mais diretos, práticos e sem muitas explicações detalhadas dos conteúdos e, muito menos, sem margem para a comunicação com os alunos, foi um desafio para Bianca: "nós, sozinhos somos mais fracos e penso que a gente nunca sabe tudo (...) eu preciso entender o que o pessoal de Pedagogia, dos anos iniciais, faz para eu melhorar o meu trabalho, acredito que elas também precisam saber o que eu preciso que eles [alunos] saibam".

A visão da professora de Matemática, em relação à mudança de concepção do seu ideário pedagógico, vai no sentido do que tem sido defendido pelo professor/pesquisador, de que tem que existir, de forma inequívoca, uma prática colaborativa entre professores de áreas específicas e áreas pedagógicas.

A diferença do olhar das participantes do grupo sobre o ensino dos conteúdos matemáticos, a partir dos diferentes níveis de atuação (Educação Infantil, anos iniciais e finais do Ensino Fundamental), possibilitou a aprendizagem colaborativa da docência, uma vez que, quando as práticas foram compartilhadas, provocaram a apropriação de conhecimentos base para a prática profissional. Em relação à percepção desta imagem de ver o assunto em questão, Bakhtin (apud FIORENTINI, 2006, p.14) contribui ao afirmar que:

O excedente de minha visão sobre o outro contém, em germe, a forma acabada do outro, cujo desabrochar requer que eu lhe complete o horizonte sem tirar a originalidade. Devo identificar-me com o outro e ver o mundo através de seu sistema de valores, tal como ele vê; devo colocar-me em seu lugar, e depois, de volta no meu lugar, contemplar seu horizonte com tudo o que se descobre do lugar que ocupo fora dele.

Não existe, em analogia com as palavras de Paulo Freire, 'saber mais ou saber menos', estamos a lidar com perfis de formação e níveis de atuação que exigem conhecimentos matemáticos específicos e, ao mesmo tempo, estratégias metodológicas e tempos de aprendizagem que diferem entre si. Neste contexto, a interação com e estas professoras, apresenta-se como fonte de aprendizagem colaborativa da docência em Matemática, desde que abandonemos a "ignorância" de acreditar que os nossos sistemas de valor, devido à posição que ocupamos nesta área do conhecimento é maior e, portanto, superior à do outro.

Temos sempre que, impreterivelmente, colocar-nos na posição do outro, seja ele professor de Matemática ou pedagogo, de compreender os seus horizontes e sistemas de representação em relação àquela área do conhecimento científico para, posteriormente, criar formas originais de colaboração e apoio em comunidades docentes. Logo, em contexto de aprendizagem colaborativa da docência, é preciso que os sujeitos ocupem o lugar um do outro, na perspectiva de compreensão das suas crenças e dos seus valores, construídos historicamente na constituição das suas identidades como professores. 
Outro dado que poderá reforçar este entendimento, reside, sem dúvida nenhuma, no reconhecimento das contribuições da professora Bianca para a prática de Alice, Paula, Sofia e Stella, quando sinalizaram a importância de ter no grupo, uma docente da área específica da matéria de ensino, que apresentou assim, uma visão orgânica do processo de interação e colaboração para aprender a ensinar no início da carreira:

\begin{abstract}
É excelente! Ajuda muito! Porque no caso, a professora de Matemática, ela nos auxilia em como lidar com a Matemática, a ensinar: "não, mas você faz assim que o aluno vai aprender melhor" e os pedagogos ensinam para ela a forma pedagógica, até mesmo porque, pelas reuniões vi que falta muito para eles, eles não têm assim muito jeito, parece, de como ensinar o aluno. Então, ter ela para nós foi uma forma de estar tirando dúvidas de como trabalhar, de como ensinar o aluno (ALICE, Naviraí-MS, 2015).

[...] a gente pode aprender muito com o professor de Matemática! No caso com a nossa colega Bianca, a gente aprende muito com ela, com as dicas dela (...) ela precisa ter contato com pedagogos porque foi o pedagogo quem "preparou" aquela criança até o quinto ano para ela estar no sexto, no sétimo (...). Então, para ela dar uma sequência e a gente, para saber como ela vai trabalhar lá, esta interação é muito relevante (PAULA, Naviraí-MS, 2015).

Eu acho que a interação, do que eu já tinha falado que eu tenho dificuldade, eu tenho dificuldade eu sou pedagoga, não sou professora de Matemática, mas ela também tem dificuldade e ela é formada em Matemática, e aí? Então, acho que é um ponto muito positivo essa interação, vejo que a minha autoestima mudou bastante, minha relação com o saber. "Eu sei” "eu não sei”, ela fala assim "ah eu também não sei isso, o que é isso?", então assim, em relação a isso mudou bastante (SOFIA, Naviraí-MS, 2015)

É interessante porque normalmente o pedagogo tem uma forma mais lúdica e tem uma visão diferente, mais ampla de todas as disciplinas e o professor de Matemática não, é só a Matemática. E normalmente (...) eles [professores de Matemática] têm aquele método de trabalhar sem a ludicidade, aquela coisa de "cheguei lá ensinei a matéria e pronto". Então, assim, acho que foi esta troca de ideia que cresceu também para o professor de Matemática trabalhar de uma forma mais pedagógica e para nós também, vermos como é a realidade dele e algumas coisas que eles trabalham para trazermos para nossa prática (STELLA, NaviraíMS, 2015).
\end{abstract}

A riqueza do trabalho com as experiências adquiridas com base na interação entre Bianca e as demais professoras, parece ter tido um "impacto" diferente na prática pedagógica de Alice, Paula, Sofia e Stella, uma vez que os relatos revelaram que o processo de aprender a ensinar Matemática, no caso pesquisado, exerceu uma grande influência das intervenções e colaboração em relação aos conhecimentos necessários à docência.

A interação entre esses dois perfis de formação para o ensino de Matemática, com os dados aqui apresentados, indicam algumas contribuições para superação das dificuldades das professoras iniciantes não só em relação à matéria de ensino como também na sua dimensão humana, como educadoras. Nos seus depoimentos, está vincadamente explicito o quanto a socialização das suas dificuldades lhes possibilitou uma análise global do processo de ensino e aprendizagem com base no diálogo e respeito com o outro e para com o outro, contribuindo para a aquisição do conhecimento matemático, na sua forma de organização e transposição didática, conforme o explicitado por Bianca, ao considerar uma melhoria no seu desempenho didático-pedagógico, a partir de seu contato com o grupo de pedagogas. Assistiu-se assim, à compreensão e importância da contextualização no ensino dos conteúdos matemáticos nas turmas de $6^{\circ}$ e $7^{\circ}$ ano: "agora eu já dou aula para o aluno e tento 
fazer uma retrospectiva do assunto, já preparar o terreno para oferecer outro conteúdo" (BIANCA, Naviraí-MS, 2015).

Nos espaços coletivos, como o grupo constituído, os professores em início de carreira sentem-se mais "tranquilos" por encontrarem outros que estão no mesmo "barco" ainda em processo de "embarque na marina". Não se sentem sozinhos porque, encontram apoio e se identificam com dificuldades semelhantes. Seguem adquirindo uma cultura formativa e, ao mesmo tempo, colaborativa num processo de interação e socialização.

O processo de reflexão é uma ação inerente à atividade humana. Contudo, a reflexão no sentido de transformação da prática social pedagógica não será possível com base na individualidade. Entendemos, a partir destas reflexões e defesas, que esse outro, pode ser entendido como a professora de Matemática e as pedagogas.

A prática reflexiva é uma importante via de desenvolvimento profissional dos professores, na medida em que esta se apresenta como uma possibilidade de mudança de concepção da atuação e, no caso das professoras principiantes, apresenta-se como fundamental para a sua socialização profissional.

A prática colaborativa envolve um significado de parceria voluntária, bem como uma relação paritária que coloca os sujeitos numa posição de igualdade perante o processo educativo.

No grupo de professoras iniciantes, essa vivência foi perceptível tanto para nós pesquisadores quanto para as participantes, o que contribui para o nosso entendimento e defesa da denominação de grupo colaborativo, espaço este sediado nesta experiência pela reflexão permanente da atuação docente.

\section{CONSIDERAÇÕES FINAIS}

Como a literatura tem apontado, o trabalho colaborativo apresenta-se como uma possibilidade para auxiliar os professores iniciantes ou experientes a partir das suas vivências na carreira. Decorre assim, a necessidade da constituição de grupos colaborativos dentro da escola.

Nesta perspectiva, a colaboração e gerenciamento dos problemas práticos da profissão podem constituir-se como elementos importantes para que a escola exerça o seu papel no processo de formação do professor iniciante. A relevância desta pesquisa está diretamente ligada à demonstração de que o trabalho colaborativo pode ser a base para a superação das dificuldades dos professores.

A problemática central apresentada neste estudo reside no processo de construção do início da docência em Matemática por professoras com perfis de formação distintos, a partir do seu ingresso na profissão e uma das ideias defendidas, como pressuposto básico, é que a colaboração pode tornar-se a base de enfrentamento e superação dos problemas em relação ao processo de ensino e aprendizagem.

Ao longo deste artigo, observa-se que a formação inicial de professores per si não tem conseguido desenvolver, nos respectivos formandos, conhecimentos e saberes acerca da atividade docente, e ainda menos, a aquisição de competências didático-pedagógicas que aproximem da realidade de como o conhecimento dos conteúdos curriculares se apresenta na sala de aula. 
Da mesma forma, com o ingresso na carreira docente, os professores iniciantes passam a lidar, cotidianamente, com sentimentos de choque de realidade, sobrevivências e descobertas, perante o desafio de ensinar o que nem sempre aprenderam: a Matemática.

Em síntese, uma das grandes contribuições para o repensar dessa realidade foi a de assumirmos posicionamento de que é preciso pensar numa formação inicial na perspectiva do desenvolvimento profissional. Para tal, na formação inicial, seria de extrema importância o curso dar a devida relevância ao desenvolvimento de diversas competências no que se refere ao saber docente. Os processos de aprender a ensinar e de aprender a profissão são de longa duração e precisam se relacionar com a teoria para solução de problemas práticos.

Por tal motivo, é relevante aprofundar estudos sobre a formação docente para que possamos compreender a reflexão do professor sobre a sua atuação, os seus sentimentos e preocupações frente à complexa construção dos seus saberes, dilemas e tudo que se vivencia no início da docência em aulas de Matemática.

Precisamos, sem dúvida, pensar num terceiro espaço formativo e, a esse lugar, podemos entendê-lo como sendo a criação de grupos de trabalho colaborativos para reflexão junto aos professores, bem como a procura de medidas coletivas para que esses profissionais se desenvolvam.

\section{REFERÊNCIAS}

CIRÍACO, K. T. Professoras iniciantes e o aprender a ensinar Matemática em um grupo colaborativo. $334 \mathrm{f}$. Tese (Doutorado em Educação) - Faculdade de Ciências e Tecnologia - Universidade Estadual Paulista, FCT/UNESP, Presidente Prudente-SP, 2016.

CRECCI, V. M.; FIOREINTINI, D. A constituição da profissionalidade docente em comunidades de investigação - o caso dos grupos colaborativos. In: $35^{a}$ Reunião Anual da ANPED, Porto de Galinhas - PE, 2012. Disponível em: < http://35reuniao.anped.org.br/images/stories/posteres/GT08/GT08-1341_int.pdf>, Acesso em: 01, out. 2015.

CRISTOVÃO, E. M. O papel da colaboração na construção de uma postura investigativa do professor de Matemática. In: CARVALHO, D. L.; CONTI, K. C. (Orgs.). Histórias de colaboração e investigação na prática pedagógica em Matemática: ultrapassando os limites da sala de aula. Campinas, SP: Alínea, 2009.

DAMIANI, M. F. Entendendo o trabalho colaborativo em educação e revelando seus benefícios. Educar, Curitiba, n. 31, p. 213-230, 2008. Disponível em: < http://www.scielo.br/pdf/er/n31/n31a13.pdf> , Acesso em: 08 set. 2013.

ENGESTRÖM, Y. Teachers as collaborative thinkers: activity-theoretical study of an innovative teacher team. In: CARLGREN, I; HANDAL, G.; VAAGE, S. Teachers' minds and actions: research on teachers` thinking and practice. London: Falmer, 1994. 
FIORENTINI, D. Pesquisar práticas colaborativas ou pesquisar colaborativamente? In: BORBA, M. de C.; ARAÚJO, J. de L. (orgs).Pesquisa qualitativa em Educação Matemática. Belo Horizonte- MG: Autêntica, 2004.

Uma história de reflexão e escrita sobre a prática escolar em matemática. In: FIORENTINI, D.; CRISTOVÃO, E. M. (Org.). Histórias e Investigação delem Aulas de Matemática. Campinas: Alínea, 2006.

FIORENTINI, D.; LORENZATO, S. Investigação em educação matemática: percursos teóricos e metodológicos. 1a ${ }^{\text {a }}$ ed. Campinas, SP: Autores Associados, 2006.

FREIRE, P. Pedagogia do oprimido. Rio de Janeiro: Paz e Terra, Freire, 2002. Educação como prática de liberdade. Paz e Terra. $1^{a}$ ed. 1967.

FULLAN, M.; HARGREAVES, A. A escola como organização aprendente: buscando uma educação de qualidade. 2. ed. Porto Alegre: Artes Médicas, 2000.

GIOVANNI, L. M. O papel dos professores e dos pesquisadores: um desafio no processo de pesquisa colaborativa. IN: MARIN, A. J.; GIOVANNI, L. M.; GUARNIERI, M. R. (Orgs.). Pesquisa com professores no início da escolarização. Araraquara, SP: Junqueira \& Marin. São Paulo, SP: FAPESP, 2009. p. 17-36.

MARTINS, S. T. F. Educação científica e atividade grupal na perspectiva sóciohistórica. Ciência \& Educação, Bauru, v. 8, n. 2, p. 227-235, 2002.

NAVIRAÍ, Mato Grosso do Sul. Roteiro de Entrevista I com professoras Alice, Bianca, Paula, Stella e Sofia. Entrevistador: Klinger Teodoro Ciríaco, março de 2013.

NAVIRAÍ, Mato Grosso do Sul. Roteiro de Entrevista II com professoras Alice, Bianca, Paula, Stella e Sofia. Entrevistador: Klinger Teodoro Ciríaco, julho de 2015.

PIMENTA, S. G. Pesquisa-ação crítico-colaborativa: construindo seu significado a partir de experiências com a formação docente. Educação e Pesquisa, São Paulo, v. 31, n. 3, p. 521539, set./dez. 2005. Disponível em: http://www.scielo.br/pdf/ep/v31n3/a13v31n3.pdf, Acesso em: 30, nov. 2015. 
TARDIF, M.; RAYMOND, D. Saberes, tempo e aprendizagem do trabalho no magistério. Educação \& Sociedade, Campinas, n.73, p. 209- 244. 2000.

Recebido em: 30/05/2017

Aprovado em: 20/07/2107 